\title{
The Natural Seasons of Western Oregon and Washington
}

\author{
TED J. ALSOP \\ Utah State University, Logan, Utah \\ (Manuscript received 17 February 1988, in final form 10 March 1989)
}

\begin{abstract}
In an effort to recognize specific key dates which identify the natural seasons of the year, the thermal record of western Oregon and Washington is subjected to automated clustering techniques. Individual natural seasons of the year are recognized by the manner in which weekly temperature maxima, minima, and means are grouped using automated clustering techniques. Beginning and ending dates of the natural seasons of western Oregon and Washington are presented.
\end{abstract}

\section{Introduction}

The annual influence of weather and climate on the activities of mankind is frequently reduced to time units called seasons. A season is generally defined as a time period of the calendar year characterized by a particular variety of recognizably homogeneous weather. Two categories of seasons are broadly popularized: cultural and natural. The cultural seasons (flu season, soccer season, holiday season, etc.) are expressions of diverse human responses to annual temperature (and sometimes precipitation) fluctuation and are nearly innumerable. On the other hand, the natural seasons (spring, summer, fall, and winter) are calendar intervals normally distinguished by homogeneous types of weather regimes, particularly annual temperature vacillations, as well as widespread changes in general atmospheric circulation (Lamb 1950).

Of meteorological importance is the identification of individual parts of the natural calendar. Barry and Perry (1973) present the beginning dates of the natural seasons as identified and published by 11 disparate investigators. Notably, Bryson and Lahey (1958) employ sundry climatic parameters to identify 12 subseasons within the traditional 4 natural seasons. Although these, and other investigators, use the same seasonal designation, no agreement exists in the average beginning date of any natural season. Of course, the fixing of a specific beginning or ending date for any natural season on a global scale is not thought to be feasible due to the independent nature of distant climatic events across the globe (Allen et al. 1940).

\section{The natural seasons}

Traditionally, the "official" beginning date of each natural season is popularized by the fact that there are

Corresponding author address: Prof. Ted J. Alsop, Department of Geography, Utah State University, Logan, UT 84322-5240. four key dates marking the position on the surface of the earth (often referred to as the subsolar point) where the sun's ray is perpendicular at solar noon. In the Northern Hemisphere, the "spring" season begins at the vernal equinox on or about 21 March, at which time the sun's ray is perpendicular at the equator. The "summer" season officially arrives at the June solstice on or about 22 June, when the subsolar point is the Tropic of Cancer which marks the northernmost position of the sun's vertical ray. Occurring on or about 21 September, the autumnal equinox ushers in the "autumn" season at which time the subsolar point is again at the equator. Finally, the December solstice, on or about 22 December, signals the first day of "winter" when the subsolar point is at the Tropic of Capricorn, the southernmost position of the sun's vertical ray. The same dates apply to the Southern Hemisphere but the natural seasons are just the reverse.

Annual expressions of meteorological phenomena, however, are more variable and dynamic than to begin or end on any of these annual traditional dates. Further, within each of these four natural seasons are subseasonal vascillations of weather characteristics that constitute time periods of nonuniform seasonality. Thermal weather events that are short-term departures from monotonic seasonal trends are referred to as cold snaps and warm spells occurring within the natural seasons. Though somewhat controversial, recurrent departures from normal seasonal trends (called meteorological singularities) are so popular that weather media and atmospheric researchers continue to give them attention (Wahl 1953; Rebman 1954; Duquet 1963; Hayden 1976; Logan 1982; and Baker et al. 1983). The purpose of this paper is to report the findings of a statistical investigation of the temperature record of the Pacific Northwest in western Oregon and Washington in an effort to identify the natural seasons of this area and generally analyze the record for climatic singularities. 


\section{The database}

The temperature database used in this study was acquired from the National Climatic Center (NCC) in Asheville, North Carolina. Spanning a period of 28 years (1948-1975), the data consist of one daily maximum and one daily minimum temperature for each of 170 official meteorological stations located in western Oregon and Washington. The weekly mean substituted for any missing diurnal data. Figure 1 illustrates the location of the 96 meteorological stations located in western Oregon and the 74 western Washington stations used in this study.

In this statistical analysis, the basic temporal unit used is the week. For the illustrations presented in this article, the time period 1-7 January constitutes Week 01, 8-14 January Week 02 , and so forth. Therefore, a single climatic event had to occur for more than five days to be significant enough to be expressed in the meteorological dataset. Daily maximum and daily minimum temperatures were averaged to obtain one weekly mean maximum and one weekly mean minimum for each station. Weekly maxima and minima were next used to calculate a weekly mean temperature for each station $($ mean $=\max +\min / 2)$. These procedures generated 52 weekly temperature maxima, minima, and means for each meteorological station in the study area forming the database which was then subjected to clustering techniques.

\section{Statistical analysis}

In order to group the variables of weekly thermal maxima, minima, and means into discrete homogeneous calendar periods, two statistical clustering techniques were employed. The fundamental goal of all clustering strategies is to obtain noncontinuous groups that have the least variability within them and the maximum differences between them. Program CLUSTER (Keniston 1978) creates similar groups by agglomeration of similar collections, or entities, which are clustered by their attributes, or characteristics. Each clustering operation may be summarized by a dendrogram of dissimilarity (Figs. 2, 3, and 4). Identical entities have zero dissimilarity and the height of an arch on the dendrogram represents the degree of dissimilarity between two clusters.

A second clustering strategy, BMDP Statistical Software (BMDP 1981), was employed to substantiate the results obtained by Program CLUSTER. BMDP cluster analysis was utilized to hierarchically amalgamate weekly temperatures into groups of greatest similarity. Beginning with 52 distinctive weeks, each step of the clustering technique joins the two most similar weeks or week clusters to form a new group until all of the weeks are in one cluster. Diagrams created by this cluster analysis closely resembled those generated by Program CLUSTER and are not presented here.

From Figs. 2, 3, and 4, a natural season is identified

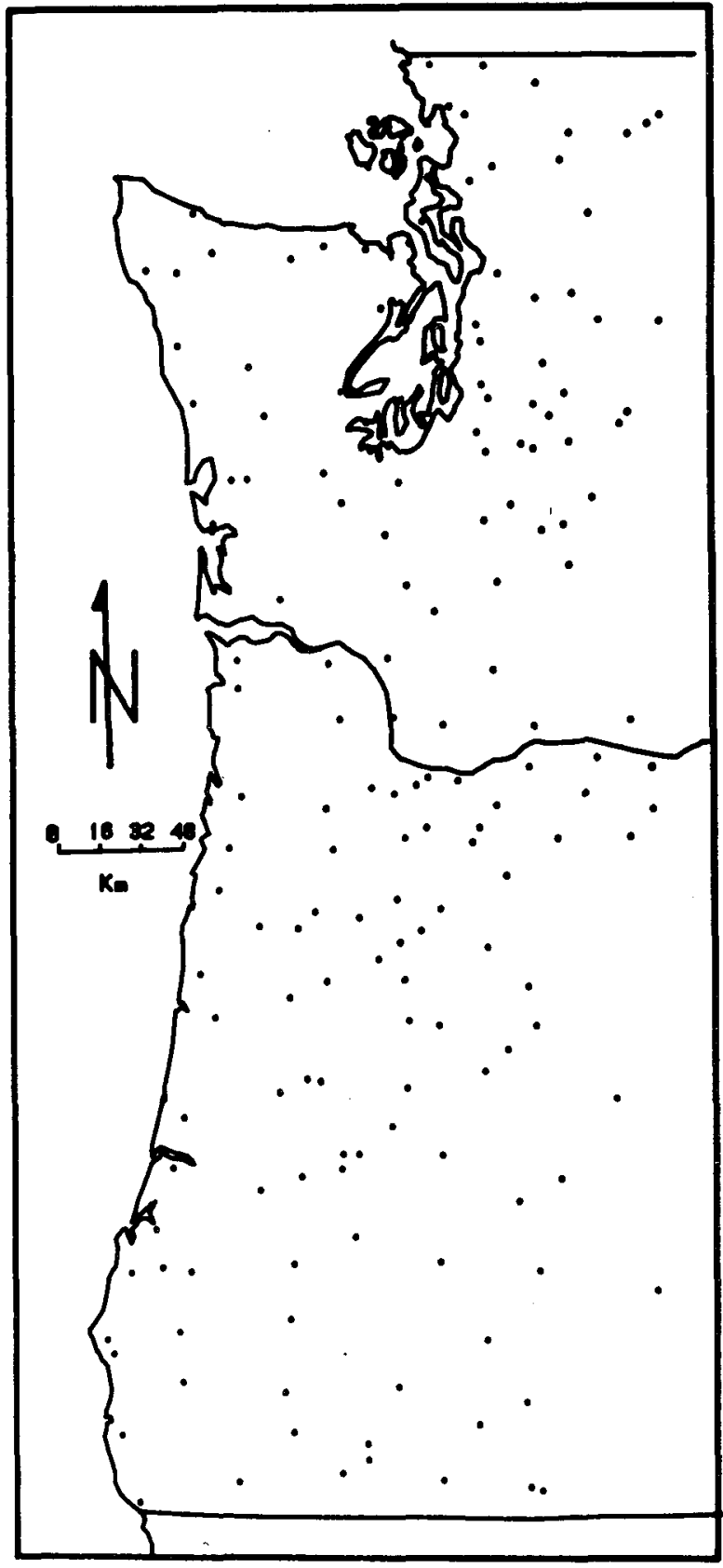

FIG. 1. Location of meteorological stations employed in this study.

as a group of chronologically adjacent weeks that is found in the same cluster of weeks as a result of the clustering technique. Subseasons are recognized by sets of sequential weeks that do not cluster together at lower dissimilarities (are less identical) and meteorological singularities are seen as a solitary week that clusters nonchronologically. Due to the high degree of autocorrelation that exists in the temperature of one week to the next, it can be observed that, at relatively low dissimilarity measures, weeks of the year remain nearly statistically identical. 


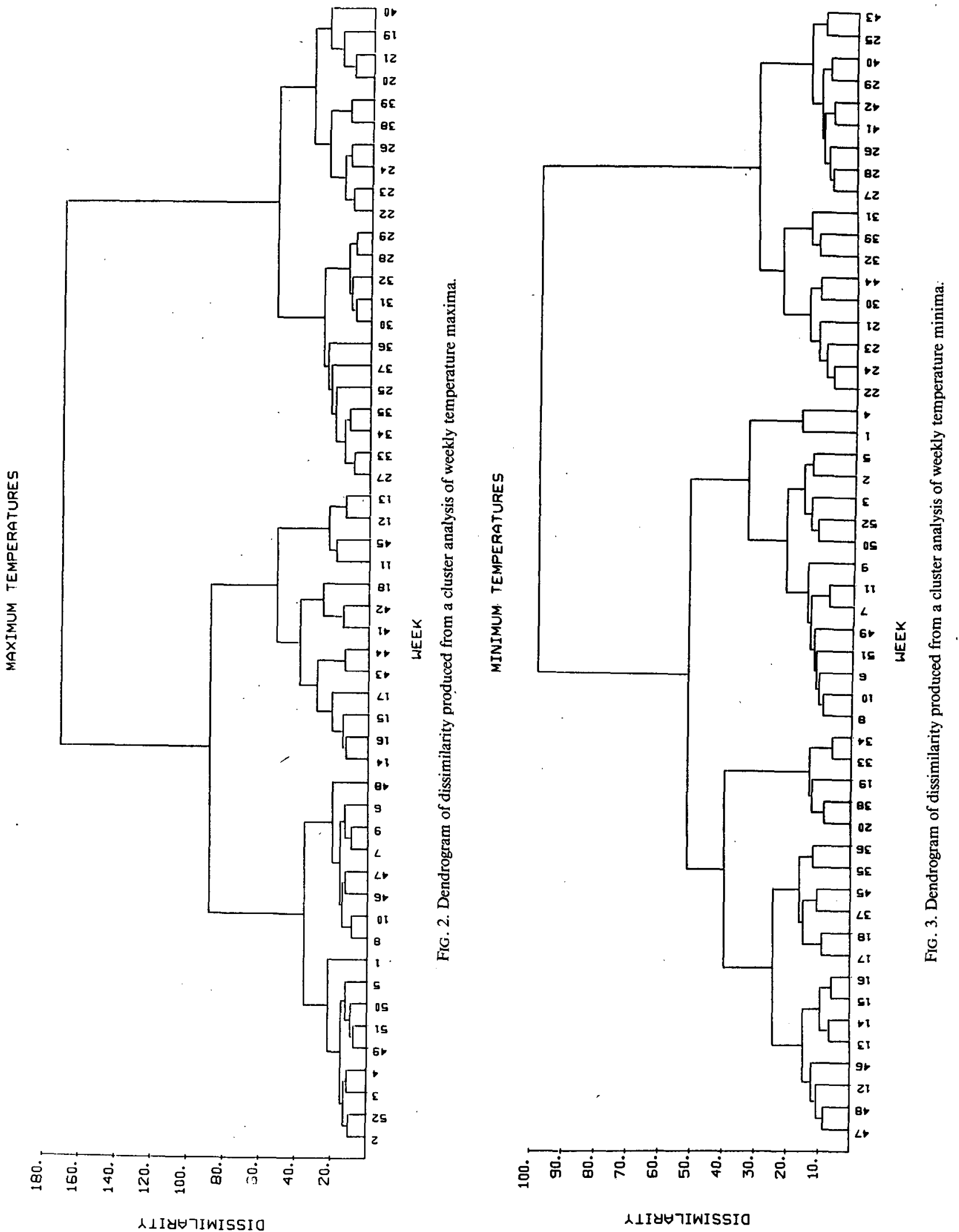




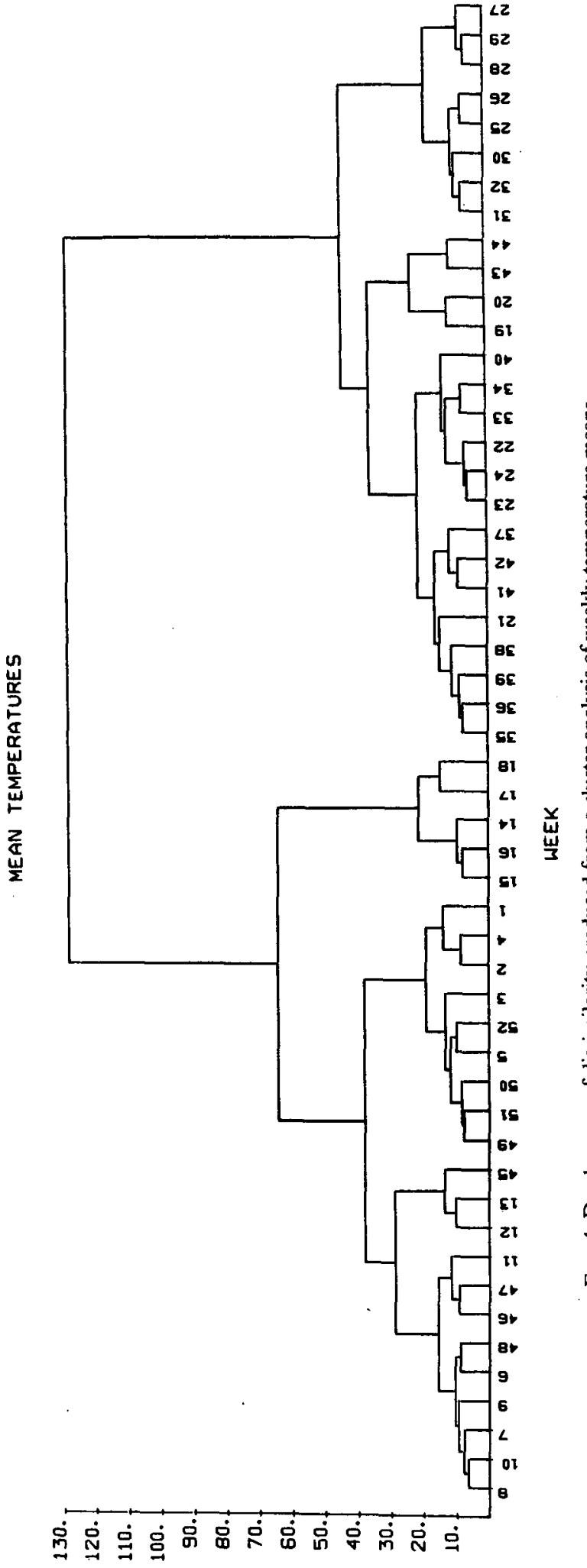

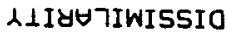

\section{Weekly maximum temperature}

Figure 2 is the dendrogram created by the stepwise clustering of weekly maximum temperature. Weeks with similar temperature maxima are found side by side connected by a short arch. Seasonal week clusters are identified by longer arches representing connecting lines. The higher the arch, the greater the dissimilarity between clustered entities. The manner in which each week or set of weeks clustered is observable by inspection of the dendrograms.

To aid in the interpretation of the dendrograms, Figs. 5,6 , and 7 summarize the stepwise clustering of weekly temperatures. Each week is presented as a hexagon while weekly groups portrayed in the dendrograms are identified by connecting lines between the hexagons. Summaries of cluster groups are presented for dissimilarity measures of $20,30,40$, and 50 in order to show the manner in which each week or set of weeks gradually clustered. With the weeks of the year arrayed in this configuration, comparisons can be made between the two extreme seasons of winter (upper portion) and summer (lower portion) and the transitional seasons of spring and autumn (center portion).

Weekly maximum temperatures display relatively large dissimilarity [measures in Fig. 2 range from 0 (the lowest statistical dissimilarity) to 180 (the highest ) ]. The single most cohesive season is that of winter, which continues from Week 46 to Week 10 ( 12 November-5 March) and spans 17 weeks. Four distinct natural seasons are not identifiable before a dissimilarity measure of 60 , which represents 33 percent of the total dissimilarity between weekly clusters.

Particularly evident is the relatively long time period that is required to heat the surface of the earth after the winter season as opposed to the relatively short time required to cool the earth's surface following the summer season. For example, at dissimilarity measure of 50 (Fig. 5), the spring cluster has eight weeks (Weeks 11-18, 12 March-30 April) while the cluster representing the autumn season contains five weeks (Weeks $41-45,8$ October -5 November). Based on the manner in which maximum weekly temperatures clustered, key dates marking the beginning of each natural season are found in Table 1.

The most striking incongruous event takes place during Week 26 (25 June-1 July) when a decrease of $3^{\circ} \mathrm{C}$ occurs, causing the maximum temperature for this week to cluster with cooler spring-season weeks. This corroborates the findings of Craddock (1956) and others who found a cool spell in the middle to late June temperature records of Europe. Conspicuously absent is strong evidence for the very popular North American meteorological singularities called the January Thaw (middle to late January) and Indian Summer (middle to late October), which are traditional warm spells in the eastern United States. 
Dissimilarity

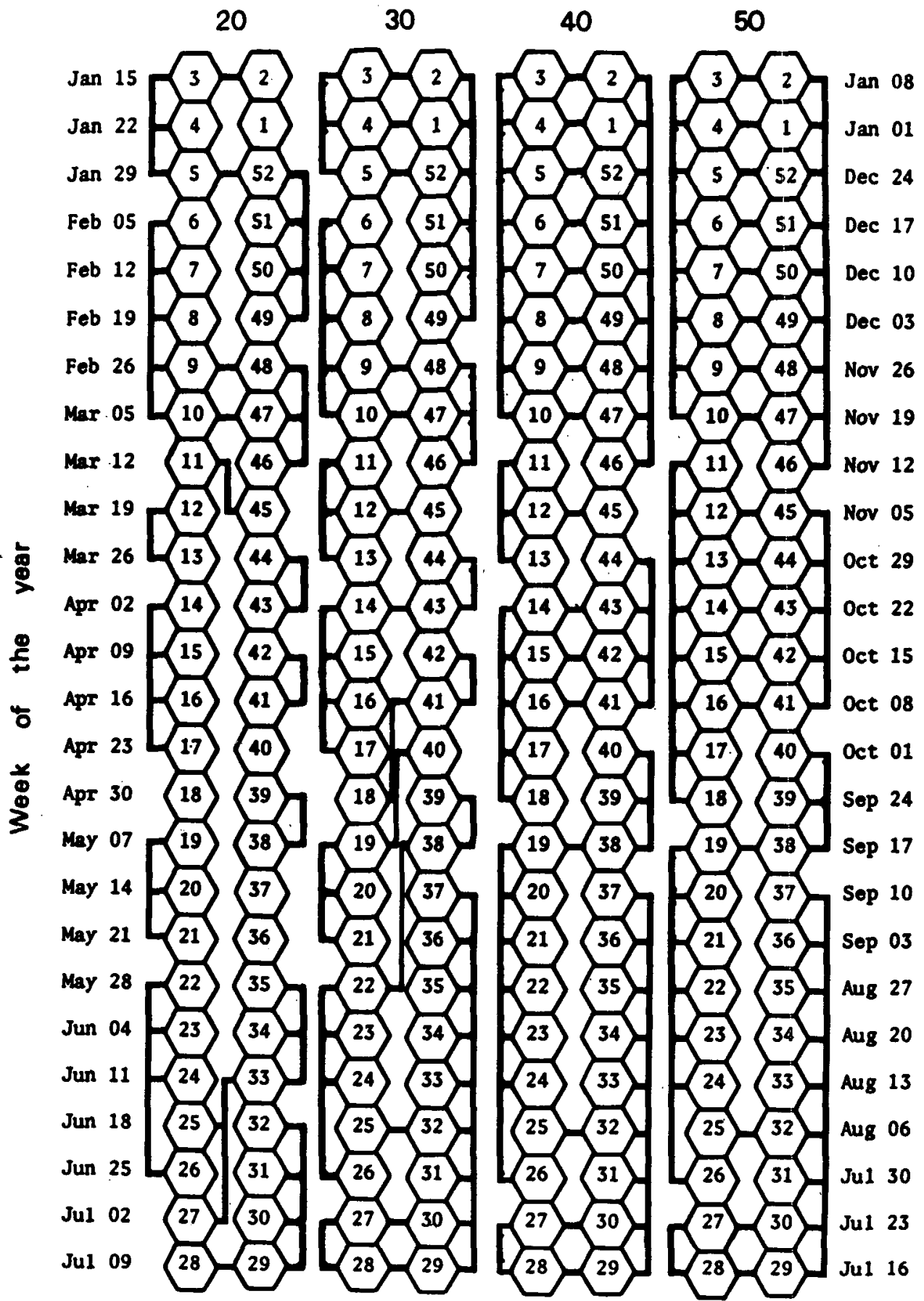

FIG. 5. Graphic summary showing stepwise clustering of weekly temperature maxima.

6. Weekly minimum temperature

The stepwise clustering of weekly minimum temperature is summarized in Fig. 6 (deciphered from Fig. 3 ). Compared to weekly maximum temperature maxima, weekly temperature minima exhibit a smaller range in dissimilarity measures $(0-100)$ suggesting that maritime influence in this region of the Pacific Northwest is a more effective moderator of minimum temperature than of maximum temperature. Though the total dissimilarity of temperature minima is lower, temperature minima clustered in chronological order 


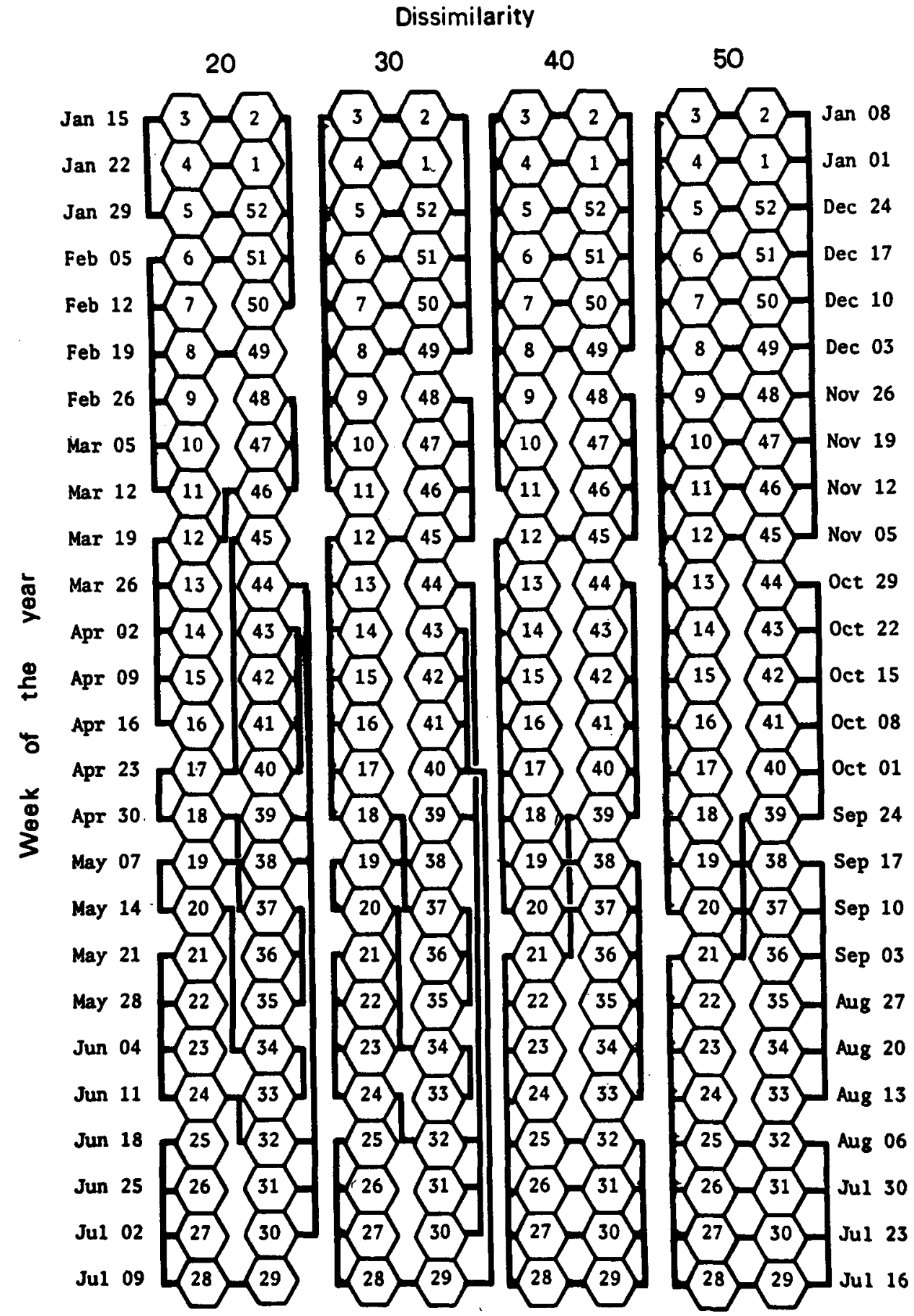

FIG. 6. Graphic summary showing stepwise clustering of weekly temperature minima.

much less well. Temporally coherent seasons are not identifiable before a dissimilarity measure of 40 , representing 40 percent of the total dissimilarity between annual minimum temperatures (Fig. 6).

At a dissimilarity measure of 50 , the year is nearly equally divided into one cold and one warm season with the exception of a six-week cooling event during
Weeks 33-38 (13 August-17 September). This annual cooling event is a response to coastal upwelling during which cooler water is brought to the oceanic surface at this time of the year (Pickard 1975).

The most conspicuous singularity is a warming event of $2{ }^{\circ} \mathrm{C}$ that occurs during Week 44 (beginning $29 \mathrm{Oc}$ tober), causing this week to cluster anachronistically 


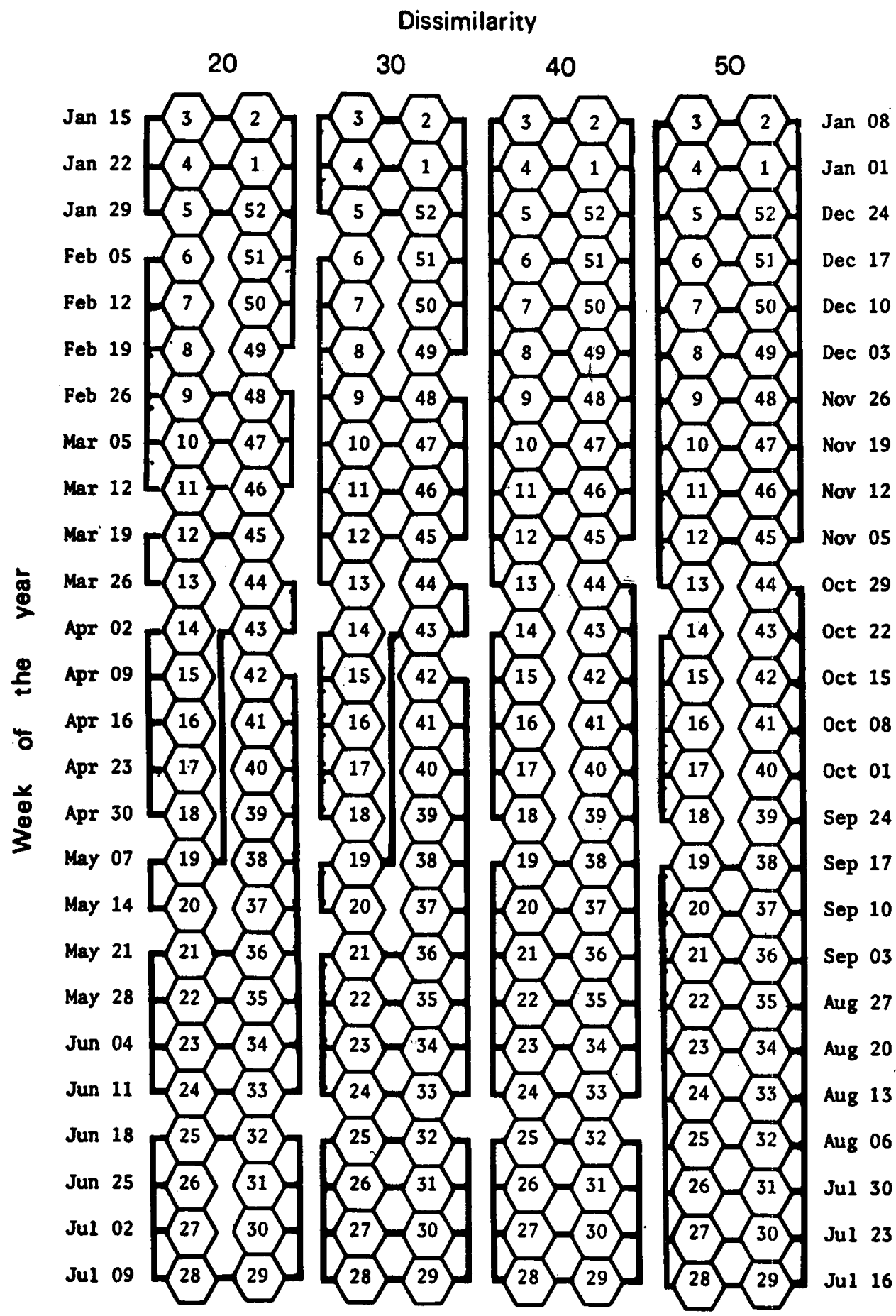

FIG. 7. Graphic summary showing stepwise clustering of weekly temperature means.

(at low dissimilarities) with warmer summer weeks. Although this minima singularity is not evident in the weekly temperature maxima, any return to near summer warmth at this time of the year is locally known as an occurrence of Indian Summer, which is called other names in different parts of the world (Wahl 1953).

\section{Weekly mean temperature}

Created from the dendrogram in Fig. 4, Fig. 7 illustrates the stepwise clustering of weekly mean temperatures calculated from $(\max +\min / 2)$. In terms of total dissimilarity, weekly mean temperatures display a general compromise between the grouping of maxi- 
TABLE 1. The clustering of weeks based on a dissimilarity measure of 40 .

\begin{tabular}{|c|c|c|c|c|c|}
\hline \multicolumn{2}{|c|}{$\begin{array}{c}\text { Maximum } \\
\text { temperature }\end{array}$} & \multicolumn{2}{|c|}{$\begin{array}{l}\text { Minimum } \\
\text { temperature }\end{array}$} & \multicolumn{2}{|c|}{$\begin{array}{c}\text { Mean } \\
\text { temperature }\end{array}$} \\
\hline \multicolumn{6}{|c|}{ Winter } \\
\hline Wk 46 & 12 Nov & Wk 49 & $03 \mathrm{Dec}$ & Wk 45 & 05 Nov \\
\hline Wk 47 & 19 Nov & Wk 50 & $10 \mathrm{Dec}$ & Wk 46 & 12 Nov \\
\hline Wk 48 & 26 Nov & Wk 51 & $17 \mathrm{Dec}$ & Wk 47 & 19 Nov \\
\hline Wk 49 & $03 \mathrm{Dec}$ & Wk 52 & $24 \mathrm{Dec}$ & Wk 48 & $26 \mathrm{Nov}$ \\
\hline Wk 50 & $10 \mathrm{Dec}$ & Wk 01 & $01 \mathrm{Jan}$ & Wk 49 & $03 \mathrm{Dec}$ \\
\hline Wk 51 & $17 \mathrm{Dec}$ & Wk 02 & 08 Jan & Wk 50 & $10 \mathrm{Dec}$ \\
\hline Wk 52 & $24 \mathrm{Dec}$ & Wk 03 & 15 Jan & Wk 51 & $17 \mathrm{Dec}$ \\
\hline Wk 01 & $01 \mathrm{Jan}$ & Wk 04 & $22 \mathrm{Jan}$ & Wk 52 & $24 \mathrm{Dec}$ \\
\hline Wk 02 & $08 \mathrm{Jan}$ & Wk 05 & 29 Jan & Wk 01 & $01 \mathrm{Jan}$ \\
\hline Wk 03 & $15 \mathrm{Jan}$ & Wk 06 & 05 Feb & Wk 02 & $08 \mathrm{Jan}$ \\
\hline Wk 04 & $22 \mathrm{Jan}$ & Wk 07 & 12 Feb & Wk 03 & 15 Jan \\
\hline Wk 05 & $29 \mathrm{Jan}$ & Wk 08 & $19 \mathrm{Feb}$ & Wk 04 & $22 \mathrm{Jan}$ \\
\hline Wk 06 & $05 \mathrm{Feb}$ & Wk 09 & $26 \mathrm{Feb}$ & Wk 05 & 29 Jan \\
\hline Wk 07 & 12 Feb & Wk 10 & 05 Mar & Wk 06 & 05 Feb \\
\hline Wk 08 & 19 Feb & Wk 11 & $12 \mathrm{Mar}$ & Wk 07 & 12 Feb \\
\hline Wk 09 & $26 \mathrm{Feb}$ & & & Wk 08 & 19 Fèb \\
\hline \multirow[t]{5}{*}{ Wk 10} & $05 \mathrm{Mar}$ & & & Wk 09 & $26 \mathrm{Feb}$ \\
\hline & & & & Wk 10 & os Mar \\
\hline & & & & Wk 11 & $12 \mathrm{Mar}$ \\
\hline & & & & Wk 12 & $19 \mathrm{Mar}$ \\
\hline & & & & Wk 13 & $26 \mathrm{Mar}$ \\
\hline
\end{tabular}

Wk $11 \quad 12 \mathrm{Mar}$

Wk 1219 Mar

Wk $1326 \mathrm{Ma}$

Wk $14 \quad 02$ Apr

Wk $15 \quad 09$ Apr

Wk $16 \quad 16 \mathrm{Apr}$

Wk $17 \quad 23$ Apr

Wk $18 \quad 30 \mathrm{Apr}$

\section{Spring}

$\begin{array}{ll}\text { Wk 12 } & \text { 19 Mar } \\ \text { Wk 13 } & \text { 26 Mar } \\ \text { Wk 14 } & \text { 02 Apr } \\ \text { Wk 15 } & \text { 09 Apr } \\ \text { Wk 16 } & 16 \mathrm{Apr} \\ \text { Wk 17 } & 23 \mathrm{Apr} \\ \text { Wk 18 } & 30 \mathrm{Apr} \\ \text { Wk 19 } & \text { 07 May } \\ \text { Wk 20 } & \text { 14 May }\end{array}$

Summer

\begin{tabular}{|c|c|c|c|c|c|}
\hline Wk 19 & 07 May & Wk 21 & 21 May & Wk 19 & 07 May \\
\hline Wk 20 & 14 May & Wk 22 & $28 \mathrm{May}$ & Wk 20 & 14 May \\
\hline Wk 21 & 21 May & Wk 23 & 04 Jun & Wk 21 & 21 May \\
\hline Wk 22 & 28 May & Wk 24 & 11 Jun & Wk 22 & $28 \mathrm{May}$ \\
\hline Wk 23 & 04 Jun & Wk 25 & $18 \mathrm{Jun}$ & Wk 23 & 04 Jun \\
\hline Wk 24 & $11 \mathrm{Jun}$ & Wk 26 & 25 Jun & Wk 24 & 11 Jun \\
\hline Wk 25 & 18 Jun & Wk 27 & $02 \mathrm{Jul}$ & Wk 25 & 18 Jun \\
\hline Wk 26 & $25 \mathrm{Jun}$ & Wk 28 & $09 \mathrm{Jul}$ & Wk 26 & 25 Jun \\
\hline Wk 27 & $02 \mathrm{Jul}$ & Wk 29 & $16 \mathrm{Jul}$ & Wk 27 & $02 \mathrm{Jul}$ \\
\hline Wk 28 & $09 \mathrm{Jul}$ & Wk 30 & $23 \mathrm{Jul}$ & Wk 28 & $09 \mathrm{Jul}$ \\
\hline Wk 29 & $16 \mathrm{Jul}$ & Wk 31 & $30 \mathrm{Jul}$ & Wk 29 & $16 \mathrm{Jul}$ \\
\hline Wk 30 & $23 \mathrm{Jul}$ & Wk 32 & 06 Aug & Wk 30 & $23 \mathrm{Jul}$ \\
\hline Wk 31 & $30 \mathrm{Jul}$ & Wk 33 & $13 \mathrm{Aug}$ & Wk 31 & $30 \mathrm{Jul}$ \\
\hline Wk 32 & 06 Aug & Wk 34 & 20 Aug & Wk 32 & 06 Aug \\
\hline Wk 33 & 13 Aug & Wk 35 & 27 Aug & & \\
\hline Wk 34 & 20 Aug & Wk 36 & 03 Sep & & \\
\hline Wk 35 & $27 \mathrm{Aug}$ & Wk 37 & $10 \mathrm{Sep}$ & & \\
\hline Wk 36 & 03 Sep & Wk 38 & $17 \mathrm{Sep}$ & & \\
\hline Wk 37 & $10 \mathrm{Sep}$ & & & & \\
\hline Wk 38 & 17 Sep & & & & \\
\hline \multicolumn{6}{|c|}{ Fall } \\
\hline Wk 39 & 24 Sep & Wk 39 & 24 Sep & Wk 33 & 13 Aug \\
\hline Wk 40 & 01 Oct & Wk 40 & 01 Oct & Wk 34 & 20 Aug \\
\hline Wk 41 & 08 Oct & Wk 41 & 08 Oct & Wk 35 & 27 Aug \\
\hline Wk 42 & 15 Oct & Wk 42 & 15 Oct & Wk 36 & 03 Sep \\
\hline Wk 43 & $22 \mathrm{Oct}$ & Wk 43 & 22 Oct & Wk 37 & 10 Sep \\
\hline Wk 44 & 29 Oct & Wk 44 & 29 Oct & Wk 38 & 17 Sep \\
\hline \multirow[t]{6}{*}{ Wk 45} & 05 Nov & Wk 45 & $05 \mathrm{Nov}$ & Wk 39 & 24 Sep \\
\hline & & Wk 46 & $12 \mathrm{Nov}$ & Wk 40 & 01 Oct \\
\hline & & Wk 47 & 19 Nov & Wk 41 & $08 \mathrm{Oct}$ \\
\hline & & Wk 48 & $26 \mathrm{Nov}$ & Wk 42 & 15 Oct \\
\hline & & & & Wk 43 & $22 \mathrm{Oct}$ \\
\hline & & & & Wk 44 & 29 Oct \\
\hline
\end{tabular}

mum and minimum temperatures. Dissimilarity measures range between 0-130 and more identical weeks are made evident by the clustering of weeks at lower dissimilarity values.

Two clusters are most-coherent: a cluster of five weeks (Weeks 14-18, 2 April-30 April), which maintains its individual identity to a dissimilarity measure of 65 , and a cluster of eight weeks (Weeks 25-32, 18 June-6 August ), distinctive to a dissimilarity measure of 50 .

In terms of unique calendar intervals, the most homogeneous natural seasons of western Oregon and Washington are spring and summer. The year is equally divided into 26 weeks of summer and 26 weeks of winter between the dissimilarity measures of 65 to 130 (Fig. 4). The midpoint of the cool season is seen to be Week 5 (beginning 29 January) while the midpoint of the warm season is Week 31 (beginning 30 July) lending strength to the wide scientific use of these months in representing the two extreme seasons.

Interestingly, Weeks 19 and 20 (7 May-20 May), which eventually become the first two weeks of the summer season, cluster early with Weeks 43 and 44 ( 22 October -4 November), which eventually become the last two weeks of fall. Inspection of the manner in which weekly mean temperatures clustered renders little evidence for any of the popularized meteorological singularities.

\section{Conclusions}

Based upon cluster analysis of weekly maximum, minimum, and mean temperature, the natural seasons of the Pacific Northwest in the United States are seen to be much more complex and numerous than merely four (Table 2). By visual inspection of dissimilarity between homogeneous weekly clusters of temperature maxima, minima, and means, the natural seasons are identified as follows:

(i) Lasting for a period of 19 weeks, the winter season with its two transitional subseasons is the longest single season (Weeks 45-11, 5 November-12 March).

(ii) Also having three subseasons, the spring season is expressed during Weeks 12-20 (19 March-14 May).

(iii) Only exceeded in length by the winter season, the summer season exists during Weeks 21-38 (21 May-17 September) and also displays two homogeneous subseasons.

(iv) The shortest of all natural seasons is fall, which consists of two subseasons between Weeks 39-44 (24 September-29 October).

With the exception of a substantial cooling event in the temperature maxima of Week 26 ( 25 June-1 July) and a less impressive warming event in the minimum temperatures of Week 44 ( 29 October-4 November), no strong evidence supports the existence of the popularized January Thaw or Indian Summer meteoro- 
TABLE 2. The natural seasons of western Oregon and Washington based on the combined clustering of temperature maxima, minima, and means at $30 \%$ of total dissimilarity.

\begin{tabular}{|c|c|c|c|c|c|c|c|c|c|}
\hline & \multicolumn{2}{|c|}{ Winter } & & \multicolumn{2}{|c|}{ Spring } & \multicolumn{2}{|c|}{ Summer } & \multicolumn{2}{|c|}{ Fall } \\
\hline ' & $\begin{array}{l}\text { Wk } 45 \\
\text { Wk } 46 \\
\text { Wk } 47 \\
\text { Wk } 48 \\
\text { Wk } 49 \\
\text { Wk } 50 \\
\text { Wk } 51 \\
\text { Wk } 52 \\
\text { Wk } 01 \\
\text { Wk } 02 \\
\text { Wk } 03 \\
\text { Wk } 04 \\
\text { Wk } 05 \\
\text { Wk } 06 \\
\text { Wk } 07 \\
\text { Wk } 08 \\
\text { Wk } 09 \\
\text { Wk } 10 \\
\text { Wk } 11\end{array}$ & $\begin{array}{l}05 \text { Nov } \\
12 \text { Nov } \\
19 \text { Nov } \\
26 \text { Nov } \\
03 \text { Dec } \\
10 \text { Dec } \\
17 \text { Dec } \\
24 \text { Dec } \\
01 \text { Jan } \\
08 \text { Jan } \\
15 \text { Jan } \\
22 \text { Jan } \\
29 \text { Jan } \\
05 \text { Feb } \\
12 \text { Feb } \\
19 \text { Feb } \\
26 \text { Feb } \\
05 \mathrm{Mar} \\
12 \mathrm{Mar}\end{array}$ & ' & $\begin{array}{l}\text { Wk } 12 \\
\text { Wk } 13 \\
\text { Wk } 14 \\
\text { Wk } 15 \\
\text { Wk } 16 \\
\text { Wk } 17 \\
\text { Wk } 18 \\
\text { Wk } 19 \\
\text { Wk } 20\end{array}$ & $\begin{array}{l}19 \mathrm{Mar} \\
26 \mathrm{Mar} \\
02 \mathrm{Apr} \\
09 \mathrm{Apr} \\
16 \mathrm{Apr} \\
23 \mathrm{Apr} \\
\mathrm{Apr} 30 \\
07 \mathrm{May} \\
14 \mathrm{May}\end{array}$ & $\begin{array}{l}\text { Wk } 21 \\
\text { Wk } 22 \\
\text { Wk } 23 \\
\text { Wk } 24 \\
\text { Wk } 25 \\
\text { Wk 26 } \\
\text { Wk } 27 \\
\text { Wk } 28 \\
\text { Wk } 29 \\
\text { Wk 30 } \\
\text { Wk 31 } \\
\text { Wk } 32 \\
\text { Wk } 33 \\
\text { Wk 34 } \\
\text { Wk } 35 \\
\text { Wk } 36 \\
\text { Wk 37 } \\
\text { Wk } 38\end{array}$ & $\begin{array}{l}21 \text { May } \\
28 \text { May } \\
04 \text { Jun } \\
11 \text { Jun } \\
\text { J Jun } \\
18 \text { Jun } \\
25 \text { Jun } \\
02 \text { Jul } \\
09 \text { Jul } \\
16 \text { Jul } \\
23 \text { Jul } \\
30 \text { Jul } \\
06 \text { Aug } \\
13 \text { Aug } \\
20 \text { Aug } \\
27 \text { Aug } \\
03 \text { Sep } \\
10 \text { Sep } \\
17 \text { Sep }\end{array}$ & $\begin{array}{l}\text { Wk } 39 \\
\text { Wk } 40 \\
\text { Wk } 41 \\
\text { Wk } 42 \\
\text { Wk } 43 \\
\text { Wk } 44\end{array}$ & $\begin{array}{l}24 \text { Sep } \\
01 \text { Oct } \\
08 \text { Oct } \\
15 \text { Oct } \\
22 \text { Oct } \\
29 \text { Oct }\end{array}$ \\
\hline
\end{tabular}

logical singularities. Maritime influence in the Pacific Northwest is seen to be a more effective moderator of temperature minima than of temperature maxima. Weekly temperature minima are much less chronologically similar than are weekly temperature maxima in western Oregon and Washington.

\section{REFERENCES}

Allen, R. A., R. Fletcher, J. Holmboe, J. Namias and H. C. Willett, 1940: Report on an experiment in five-day weather forecasting. Physical Oceanography and Meteorology, Massachusetts Institute of Technology, Woods Hole Oceanography Institute, 8(3).

Baker, D. G., J. C. Klink and R. H. Skaggs, 1983: Singularity in clear-day frequencies in the north-central region. Mon. Wea. Rev., 111, 895-898.

Barry, R. G., and A. H. Perry, 1973: Synoptic Climatology. Methuen \& Co., Ltd.

BMDP Statistical Software. 1981. University of California Press.
Bryson, R. A., and J. F. Lahey, 1958: The March of the Seasons. University of Wisconsin, $41 \mathrm{pp}$.

Craddock, J. M., 1956: The representation of the annual temperature variation over central and northern Europe by a two-term harmonic form. Quart. J. Roy. Meteor. Soc., 82, 275-288.

Duquet, R. T., 1963:- The January warm spell and associated largescale circulation changes. Mon. Wea. Rev., 91, 47-60.

Hayden, B. P., 1976: January-Thaw singularity and wave climates along the eastern coast of the USA. Nature, 263, 491-492.

Keniston, J. A., 1978: Program CLUSTER: an aid to numerical classification using the CDC cyber computer. Pliuronectic Project Tech. Rep. No. 2. Oregon State University.

Lamb, H. H., 1950: Types and spells of weather around the year in the British Isles: annual trends, seasonal structure of the year, singularities. Quart. J. Roy. Meteor. Soc., 76, 393-429.

Logan, R., 1982: The January thaw. Weatherwise, 35, 263-267.

Pickard, G. L., 1975: Descriptive Physical Oceanography, 2nd Ed. Pergamon Press.

Rebman, E. J., 1954: January temperature profile, Victoria, BC-A west coast singularity. Weather, 9, 131-136.

Wahl, E. W., 1953: Singularities and the general circulation. J. Meteor., 10, 42-45. 